Article

\title{
Novel Pb(II) Complexes: X-Ray Structures, Hirshfeld Surface Analysis and DFT Calculations
}

\author{
Ghodrat Mahmoudi ${ }^{1, *(\mathbb{C})}$, Saikat Kumar Seth ${ }^{2}{ }^{(0}$, Antonio Bauza Riera ${ }^{3, * \mathbb{C}}$, \\ Fedor Ivanovich Zubkov ${ }^{4}\left(\right.$ ) and Antonio Frontera ${ }^{3}$ (i) \\ 1 Department of Chemistry, Faculty of Science, University of Maragheh, 55181-83111 Maragheh, Iran \\ 2 Department of Physics, Jadavpur University, Kolkata 700032, India; saikatim@yahoo.co.in \\ 3 Departament de Química, Universitat de les Illes Balears, Crta. de Valldemossa km 7.5, \\ 07122 Palma de Mallorca (Baleares), Spain; antonio.bauza@uib.es \\ 4 Organic Chemistry Department, Faculty of Science, Peoples' Friendship University of Russia \\ (RUDN University), Miklukho-Maklaya Str. 6, Moscow 117198, Russian; fzubkov@sci.pfu.edu.ru \\ * Correspondence: ghodratmahmoudi@gmail.com (G.M.); toni.frontera@uib.es (A.B.R.)
}

Received: 5 June 2020; Accepted: 29 June 2020; Published: 2 July 2020

check for updates

\begin{abstract}
Herein we report the synthesis and detailed structural characterization of two new centrosymmetric dinuclear coordination compounds of $\mathrm{Pb}$ (II) $\left[\mathrm{Pb}_{2} \mathrm{~L}_{2}(\mathrm{NCS})_{4}\right]$ (1) and $\left[\mathrm{Pb}_{2} \mathrm{~L}_{2}\left(\mathrm{NO}_{3}\right)_{4}\right] \cdot 2 \mathrm{MeOH}$ (2), using the organic ligand 1,2-diphenyl-1,2-bis((methyl(pyridin2-yl)methylene)hydrazono)ethane (L). In both complexes, each subunit $\left[\mathrm{PbLX}_{2}\left(\mathrm{X}=\mathrm{NO}_{3}\right.\right.$ or NCS)] adopts a quasi-aromatic Möbius metal chelate structure. Each ligand $\mathrm{L}$ is coordinated in a tetradentate coordination mode to $\mathrm{Pb}(\mathrm{II})$, yielding the $12 \pi$ electron chelate ring via two pyridyl-imine units. In compound (1), the coordination sphere is completed by one disordered $\mathrm{N}, \mathrm{S}$-coordinated thiocyanate anion and two $\mu_{1,1}$-bridging $\mathrm{N}$-coordinated thiocyanate anions. In compound (2), the coordination sphere of $\mathrm{Pb}$ (II) is completed by two monodentate and two bidentate nitrato ligands (two of them acting as bridging ligands). Crystal packing of both compounds is stabilized by intermolecular hydrogen bonds, intra- and intermolecular $\mathrm{C}-\mathrm{H} \cdots \pi$ interactions. The Hirshfeld molecular surfaces of (1) and (2) demonstrate that their packing is dominated by $\mathrm{C}-\mathrm{H} \cdots \mathrm{O} / \mathrm{N} / \mathrm{S}$ interactions as well as by far less favored $\mathrm{H} \cdots \mathrm{H}$ contacts.
\end{abstract}

Keywords: $\mathrm{Pb}(\mathrm{II})$ complexes; noncovalent interactions; hirshfeld surface analysis; DFT calculations

\section{Introduction}

The development of new ligands capable of trapping $\mathrm{Pb}(\mathrm{II})$ is of continuous interest [1]. The rich and versatile coordination chemistry of $\mathrm{Pb}$ (II) is related to its large size in combination with the presence of a $6 s^{2}$ electron pair, which can remain inert or stereoactive [2]. In fact, the coordination number usually ranges from four to nine. This extraordinary versatility has been exploited for the preparation of a variety of hybrid inorganic-organic polymers and complexes [3-5]. In spite of the negative implications of lead related to health and environmental issues, it is used for the production of materials with interesting properties like semiconductors, NLO (non-linear optical) and ferroelectric materials [6].

In supramolecular chemistry, hemi-directionally coordinated complexes of $\mathrm{Pb}$ (II) have been utilized to construct a variety of supramolecular assemblies based on tetrel bonding interactions [7-9] and metal organic frameworks (MOFs) [10].

In the present work, the tetradentate 1,2-diphenyl-1,2-bis((methyl(pyridin-2-yl)methylene)hydrazono) ethane $\mathrm{N}_{4}$-ligand has been used to prepare and $\mathrm{X}$-ray which characterizes two new dinuclear lead(II) complexes (see Scheme 1): $\left[\mathrm{Pb}_{2}(\mathrm{~L})_{2}(\mathrm{SCN})_{4}\right](\mathbf{1})$ and $\left[\mathrm{Pb}_{2}(\mathrm{~L})_{2}\left(\mathrm{NO}_{3}\right)_{2}\right] 2 \mathrm{MeOH}(2)$. 
Moreover, supramolecular assemblies have been studied using Hirshfeld surface analyses and rationalized using molecular electrostatic potential (MEP) surface calculations. In these complexes the conventional coordination number is $n \geq 7$ and consequently holodirected coordination mode is observed.

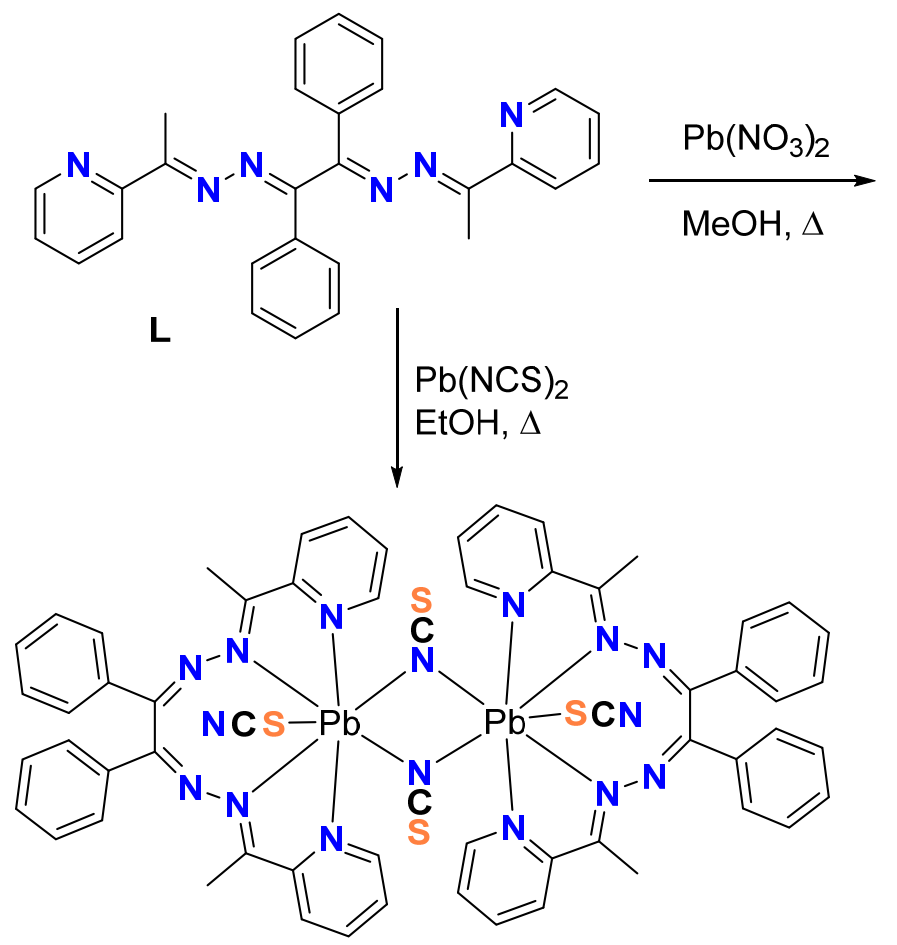

$\left[\mathrm{Pb}_{2} \mathrm{~L}_{2}(\mathrm{SCN})_{4}\right]$, (1)

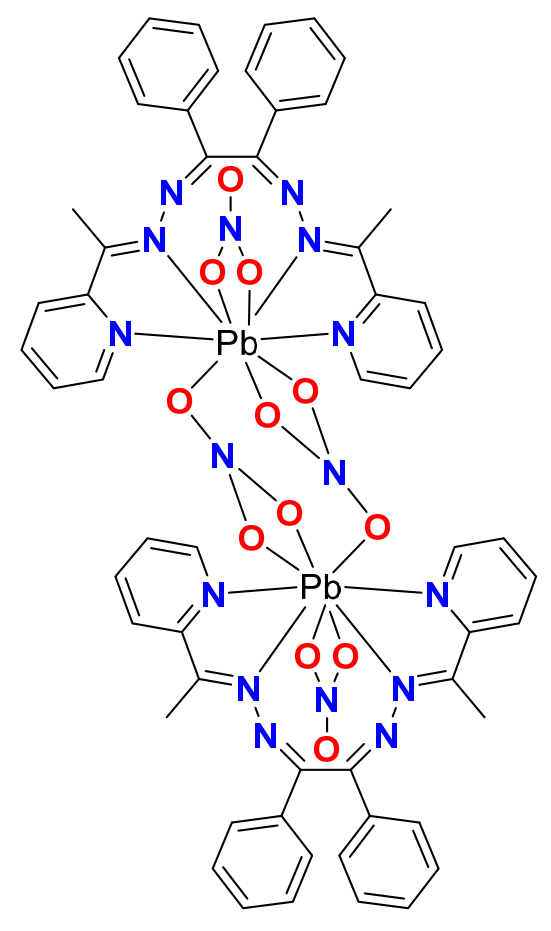

$\left[\mathrm{Pb}_{2} \mathrm{~L}_{2}\left(\mathrm{NO}_{3}\right)_{4}\right],(2)$

Scheme 1. Synthesis of complexes $\left[\mathrm{Pb}_{2} \mathrm{~L}_{2}(\mathrm{NCS})_{4}\right](\mathbf{1})$ and $\left[\mathrm{Pb}_{2} \mathrm{~L}_{2}\left(\mathrm{NO}_{3}\right)_{4}\right](2)$.

In both structures each $\mathrm{PbLX}_{2}$ subunit adopts a quasi-aromatic Möbius metal chelate structure which has been discussed in the literature [11-16]. Particularly, the complexation ability of $L$ and other related $\mathrm{N}_{6}$-tetradentate ligands to yield complexes with a quasi-aromatic Möbius topology has been extensively analyzed [17-25]. The complexes reported herein further demonstrate that quasi-aromatic structures with a Möbius topology are feasible for the $\mathrm{Pb}(\mathrm{II})$ metal center. The $12 \pi$ electron chelate ring of the PbL fragment (see Scheme 1) is a Möbius object and therefore aromatic, as previously demonstrated in several works $[19,21,26]$.

\section{Materials and Methods}

\subsection{Reagents}

All reactants were used as received without further purification. The ligand was synthesized following the protocol available in the literature [26].

\subsection{Crystallography}

Single crystal X-ray diffraction data was collected at 293(2)K by using a Bruker APEX-II CCD diffractometer (Bruker, Karlsruhe, Germany) with MoK $\alpha$ radiation $(\lambda=0.71073 \AA)$. The Bruker SAINT [27] program was used for data reduction and absorption correction was performed through the multi-scan method [28]. The title structures were solved by direct method through the program SHELXS-14 [29] and then refined by SHELXL-18 [30]. The calculations were performed using the programs WinGX V2014.1 [31] and PLATON [32]. The details of crystal data and structure refinement factors are included in Table 1. CCDC 2005501-2005502 contain the crystallographic data. 
Table 1. Crystal data and structure refinement parameters for compounds (1) and (2).

\begin{tabular}{|c|c|c|}
\hline Structure & (1) & (2) \\
\hline Empirical formula & $\mathrm{C}_{60} \mathrm{H}_{48} \mathrm{~N}_{16} \mathrm{~Pb}_{2} \mathrm{~S}_{4}$ & $\mathrm{C}_{57} \mathrm{H}_{52} \mathrm{~N}_{16} \mathrm{O}_{13} \mathrm{~Pb}_{2}$ \\
\hline Formula Weight & 1535.76 & 1583.52 \\
\hline Temperature (K) & $100(2)$ & $100(2)$ \\
\hline Wavelength $(\AA)$ & 0.71073 & 0.71073 \\
\hline Crystal system & Triclinic & Triclinic \\
\hline space group & P-1 & P-1 \\
\hline$a, b, c(\AA)$ & $9.2815(7), 10.4330(8), 16.3791(11)$ & $10.0664(6), 11.0250(7), 14.1786(10)$ \\
\hline$\alpha, \beta, \gamma\left({ }^{\circ}\right)$ & $81.444(3), 74.809(3), 78.168(4)$ & $105.444(3), 95.245(3), 104.866(3)$ \\
\hline Volume $\left(\AA^{3}\right)$ & $1490.51(19)$ & $1444.27(16)$ \\
\hline $\mathrm{Z} /$ Density (calc.) $\left(\mathrm{Mg} / \mathrm{m}^{3}\right)$ & $1 / 1.711$ & $1 / 1.821$ \\
\hline Absorption coefficient $\left(\mathrm{mm}^{-1}\right)$ & 5.834 & 5.901 \\
\hline $\mathrm{F}(000)$ & 748 & 774 \\
\hline Crystal size $\left(\mathrm{mm}^{3}\right)$ & $0.45 \times 0.40 \times 0.20$ & $0.45 \times 0.25 \times 0.11$ \\
\hline$\theta$ range for data collection & 2.274 to 25.342 & 1.512 to 26.242 \\
\hline Completeness to $\theta(\%)$ & 99.8 & 98.9 \\
\hline Absorption correction & Semi-empirical from equivalents & Semi-empirical from equivalents \\
\hline Max. and min. transmission & 0.362 and 0.154 & 0.552 and 0.165 \\
\hline Refinement method & Full-matrix least-squares on $\mathrm{F}^{2}$ & Full-matrix least-squares on $\mathrm{F}^{2}$ \\
\hline Data/parameters & $5442 / 382$ & $5905 / 416$ \\
\hline Goodness-of - fit on $\mathrm{F}^{2}$ & 1.028 & 1.051 \\
\hline Final $R$ indices $[I>2 \sigma(I)]$ & $\mathrm{R}_{1}=0.0283, \mathrm{w} \mathrm{R}_{2}=0.0581$ & $\mathrm{R}_{1}=0.0265, w \mathrm{R}_{2}=0.0529$ \\
\hline $\mathrm{R}$ indices (all data) & $\mathrm{R}_{1}=0.0337, \mathrm{wR}_{2}=0.0600$ & $\mathrm{R}_{1}=0.0323, w \mathrm{R}_{2}=0.0548$ \\
\hline Largest diff. peak and hole $\left(\mathrm{e} . \AA^{-3}\right)$ & 1.279 and -1.814 & 1.127 and -1.132 \\
\hline
\end{tabular}

\subsection{Other Physical Measurements}

Microanalyses were performed using a Heraeus CHN-O-Rapid analyser (Heraeus, Hanau, Germany). The FTIR spectra were recorded on a Bruker Tensor 27 FTIR spectrometer (Bruker, Karlsruhe, Germany).

\subsection{Synthesis}

Complexes were synthesized using a methodology consisting of the utilization of a branched tube as described in the literature [26]. A suspension of $\mathrm{L}(0.222 \mathrm{~g})$ and $\mathrm{Pb}(\mathrm{NCS})_{2}$ or $\mathrm{Pb}\left(\mathrm{NO}_{3}\right)_{2}$ ( 0.162 and $0.166 \mathrm{~g}$, respectively; $0.5 \mathrm{mmol}$ ) was placed in the main arm of a branched tube. EtOH or $\mathrm{MeOH}(15 \mathrm{~mL})$ was carefully added to fill the arms. The tube was sealed and immersed in an oil bath at $60{ }^{\circ} \mathrm{C}$ while the branched arm was kept at ambient temperature. After about one week, X-ray suitable single crystals of the corresponding complex were formed in the cooler arm of the tube. Crystals were isolated by filtration.

\subsection{1. $\left.\left[\mathrm{Pb}_{2} \mathrm{~L}_{2}(\mathrm{NCS})_{4}\right)\right](\mathbf{1})$}

Yield: $0.245 \mathrm{~g}\left(64 \%\right.$ based on Pb). FTIR, v: $1590(\mathrm{C}=\mathrm{N}), 2061$ (NCS), $2922(\mathrm{CH}) \mathrm{cm}^{-1}$. Anal. Calc. for $\mathrm{C}_{30} \mathrm{H}_{24} \mathrm{~N}_{8} \mathrm{PbS}_{2}$ (768.13): C 46.92, H 3.15 and N 14.95; found: C 47.11, H 3.28 and N 15.02\%.

\subsection{2. $\left.\left[\mathrm{Pb}_{2} \mathrm{~L}_{2}\left(\mathrm{NO}_{3}\right)_{4}\right)\right] \cdot 2 \mathrm{MeOH}(2)$}

Yield: $0.310 \mathrm{~g}\left(80 \%\right.$ based on Pb). FTIR, v: $1589(\mathrm{C}=\mathrm{N}), 1384(\mathrm{~N}-\mathrm{O}), 2982(\mathrm{CH}) \mathrm{cm}^{-1}$. Anal. Calc. for $\mathrm{C}_{28} \mathrm{H}_{24} \mathrm{~N}_{8} \mathrm{O}_{6} \mathrm{~Pb}$ (776.16): C 43.35, H 3.12 and N 14.44; found: C 43.11, H 3.21 and N 14.32\%.

\subsection{Hirshfeld Surface Analysis}

The molecular Hirshfeld surface [33-35] depends on the molecular electron distribution. By using Equation (1), the normalized contact distance $\left(d_{n o r m}\right)$ is calculated by identifying both internal and 
external intermolecular contacts simultaneously [36]. $d_{i}$ and $d_{e}$ are the distances from the point to the nearest nucleus internal and external to the surface respectively. $r_{i}^{v d w}$ and $r_{e}^{v d w}$ are the internal and external van der Waals ( $\mathrm{vd} W$ ) radii. The 2D fingerprint plot [3-40] provides all intermolecular contacts that are involved in the crystal structures. The Hirshfeld surfaces were calculated by using the program CrystalExplorer [41].

$$
d_{n o r m}=\frac{d_{i}-r_{i}^{v d w}}{r_{i}^{v d w}}+\frac{d_{e}-r_{e}^{v d w}}{r_{e}^{v d w}} \mathrm{eq}
$$

\subsection{Theoretical Methods}

Gaussian-16 program [42] was used to carry out the DFT calculations. The PBE1PBE-D3/def2-TZVP level of theory [43-46] was employed for computing the molecular electrostatic potential (MEP) using the crystallographic coordinates. The 0.001 a.u. isosurface was used for plotting the MEP.

\section{Results and Discussion}

\subsection{Synthetic Considerations}

The reaction of a suspension of either $\mathrm{Pb}(\mathrm{NCS})_{2}$ or $\mathrm{Pb}\left(\mathrm{NO}_{3}\right)_{2}$ with $\mathbf{L}$ in a branched tube apparatus at $60{ }^{\circ} \mathrm{C}$ in $\mathrm{MeOH}$ yields dinuclear discrete complexes (1) and (2) in moderate to good yields, as represented in Scheme 1.

\subsection{Structural Description}

Complex (1) crystallizes in the triclinic space group $P-1$ with half of the dinuclear complex in the asymmetric unit, as represented in Figure 1. Each metal center is seven-coordinated by two pyridyl-imine units of the parent ligand $\mathrm{L}$, one disordered terminal thiocyanate anion and two bridging $\mathrm{N}$-coordinated thiocyanate anions. The $\mathrm{S}(1), \mathrm{C}(30)$ and $\mathrm{N}(8)$ atoms of the terminal thiocyanate anion are disordered over two sets of sites with refined occupancies 0.880(7) and 0.120(7). Each L exhibits a $\mu^{4}$-coordination mode towards $\mathrm{Pb}$ (II). The $\mathrm{Pb}-\mathrm{N}_{\mathrm{Py}}$ distances are slightly longer than the $\mathrm{Pb}-\mathrm{N}_{\text {imine }}$ ones within the same pyridyl-imine fragment (see Table 2).

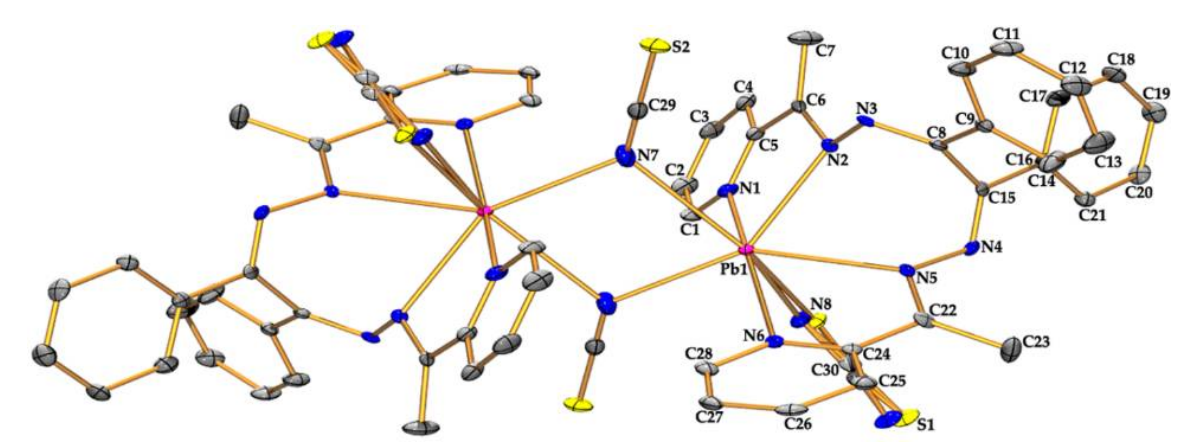

Figure 1. View of the asymmetric unit of compound (1) with a partial atom numbering scheme. Hydrogen atoms are omitted for clarity. The unlabeled counterpart is generated through the symmetry operation. Thermal ellipsoids are drawn at the $30 \%$ probability level. 
Table 2. Selected $(\AA)$ and bond angles $\left(^{\circ}\right)$ for compounds (1) and (2) as determined by X-ray diffraction.

\begin{tabular}{cccc}
\hline \multicolumn{4}{c}{ Complex $-(1)$} \\
$\mathrm{Pb}(1)-\mathrm{N}(1)$ & $2.629(4)$ & $\mathrm{Pb}(1)-\mathrm{N}(6)$ & $2.657(3)$ \\
$\mathrm{Pb}(1)-\mathrm{N}(2)$ & $2.645(3)$ & $\mathrm{Pb}(1)-\mathrm{N}(7)$ & $2.615(4)$ \\
$\mathrm{Pb}(1)-\mathrm{N}(5)$ & $2.745(3)$ & $\mathrm{Pb}(1)-\mathrm{S}(1)$ & $2.756(2)$ \\
$\mathrm{O}(1)-\mathrm{Pb}(1)-\mathrm{N}(3)$ & $60.39(9)$ & $\mathrm{O}(1)-\mathrm{Pb}(1)-\mathrm{O}(7)$ & $142.78(7)$ \\
$\mathrm{O}(1)-\mathrm{Pb}(1)-\mathrm{N}(4)$ & $115.35(9)$ & $\mathrm{N}(3)-\mathrm{Pb}(1)-\mathrm{O}(7)$ & $117.30(7)$ \\
$\mathrm{N}(3)-\mathrm{Pb}(1)-\mathrm{N}(4)$ & $57.86(9)$ & $\mathrm{N}(4)-\mathrm{Pb}(1)-\mathrm{O}(7)$ & $84.17(6)$ \\
\multicolumn{4}{c}{ Complex-(2) } \\
$\mathrm{Pb}(1)-\mathrm{O}(1)$ & $2.614(3)$ & $\mathrm{Pb}(1)-\mathrm{N}(1)$ & $2.720(3)$ \\
$\mathrm{Pb}(1)-\mathrm{O}(3)$ & $2.621(3)$ & $\mathrm{Pb}(1)-\mathrm{N}(5)$ & $2.763(3)$ \\
$\mathrm{Pb}(1)-\mathrm{N}(2)$ & $2.670(3)$ & & \\
$\mathrm{O}(1)-\mathrm{Pb}(1)-\mathrm{O}(3)$ & $48.61(8)$ & $\mathrm{N}(2)-\mathrm{Pb}(1)-\mathrm{N}(1)$ & $59.79(9)$ \\
$\mathrm{O}(1)-\mathrm{Pb}(1)-\mathrm{N}(2)$ & $75.78(9)$ & $\mathrm{O}(1)-\mathrm{Pb}(1)-\mathrm{N}(5)$ & $130.88(9)$ \\
$\mathrm{O}(3)-\mathrm{Pb}(1)-\mathrm{N}(2)$ & $81.63(9)$ & $\mathrm{O}(3)-\mathrm{Pb}(1)-\mathrm{N}(5)$ & $90.89(9)$ \\
$\mathrm{O}(1)-\mathrm{Pb}(1)-\mathrm{N}(1)$ & $70.93(9)$ & $\mathrm{N}(2)-\mathrm{Pb}(1)-\mathrm{N}(5)$ & $71.13(8)$ \\
$\mathrm{O}(3)-\mathrm{Pb}(1)-\mathrm{N}(1)$ & $114.86(9)$ & $\mathrm{N}(1)-\mathrm{Pb}(1)-\mathrm{N}(5)$ & $118.16(8)$ \\
\hline
\end{tabular}

Compound (1) exhibits $\mathrm{C}-\mathrm{H} \cdots \mathrm{N}$ and $\mathrm{C}-\mathrm{H} \cdots \mathrm{S}$ unconventional hydrogen-bonding contacts (see Table 3 ) and $\mathrm{C}-\mathrm{H} \cdots \pi$ interactions (see Table 4). The unconventional $\mathrm{H}$-bonds involve (see Figure 2 ) the thiocianate group as $\mathrm{H}$-bond acceptor and $\mathrm{C}-\mathrm{H}$ donors belonging to the methyl or pyridine groups. The acidity of the $\mathrm{H}$-atoms that participate in the $\mathrm{H}$-bonding interactions is enhanced due to the coordination of the ligand (L) to the $\mathrm{Pb}$ (II) metal center, as further analyzed below. The $\mathrm{C}-\mathrm{H} \cdots \pi$ interactions are represented in Figure 3, where one carbon atom $\mathrm{C}(2)$ of the pyridine ring is in contact with the centroid of another pyridine ring $(\mathrm{N} 6 / \mathrm{C} 24-\mathrm{C} 28)$ at $(1+\mathrm{x}, \mathrm{y}, \mathrm{z})$ by leading the molecules to propagate along the [100] direction. Moreover, one methyl hydrogen atom (C23-H23) interacts with the centroid of the aryl ring $(\mathrm{C} 16-\mathrm{C} 21)$ of the partner molecule at $(-\mathrm{x}, 2-\mathrm{y}, 1-\mathrm{z})$. This interconnection of the parallel chains leads to the formation of a supramolecular assembly in the (101) plane as depicted in Figure 3.

Table 3. Relevant hydrogen bonding parameters of compounds (1) and (2).

\begin{tabular}{|c|c|c|c|c|c|}
\hline $\mathrm{D}-\mathrm{H} \cdots \mathrm{A}$ & D-H & $\mathbf{H} \cdots \mathbf{A}$ & D $\cdots A$ & $\mathrm{D}-\mathbf{H} \cdots \mathbf{A}$ & Symmetry \\
\hline \multicolumn{6}{|c|}{ Compound (1) } \\
\hline C27-H27‥S2 & 0.95 & 2.94 & $3.716(5)$ & 139 & $1-x, 2-y,-z$ \\
\hline C7-H7C $\cdots \mathrm{N} 8$ & 0.98 & 2.64 & $3.56(2)$ & 158 & $x, 1+y, z$ \\
\hline \multicolumn{6}{|c|}{ Compound (2) } \\
\hline O7-H71‥O3 & 0.84 & 2.04 & $2.849(8)$ & 162 & - \\
\hline 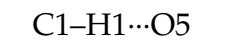 & 0.95 & 2.26 & $3.041(5)$ & 139 & $-\mathrm{x}, 1-\mathrm{y},-\mathrm{z}$ \\
\hline $\mathrm{C} 3-\mathrm{H} 3 \cdots \mathrm{O} 2$ & 0.95 & 2.57 & $3.451(5)$ & 153 & $-1+x, y, z$ \\
\hline C4-H4 $\cdots$ O7 & 0.95 & 2.40 & $3.218(9)$ & 144 & $-1+x, y, z$ \\
\hline C7-H7B ‥N3 & 0.98 & 2.55 & $3.373(5)$ & 141 & $-x, 1-y, 1-z$ \\
\hline C7-H7C $\cdots \mathrm{N} 3$ & 0.98 & 2.30 & $2.755(5)$ & 107 & - \\
\hline $\mathrm{C} 12-\mathrm{H} 12 \cdots \mathrm{O} 1$ & 0.95 & 2.47 & $3.102(6)$ & 124 & $x,-1+y, z$ \\
\hline C15-H15B $\cdots \mathrm{O} 7$ & 1.40 & 2.40 & $3.574(9)$ & 139 & - \\
\hline 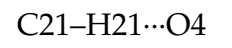 & 0.95 & 2.57 & $3.243(5)$ & 128 & $-1-x,-y,-z$ \\
\hline $\mathrm{C} 23-\mathrm{H} 23 \mathrm{C} \cdots \mathrm{N} 4$ & 0.98 & 2.39 & $2.789(5)$ & 104 & - \\
\hline C29-H29...O4 & 0.95 & 2.41 & $3.161(5)$ & 136 & $-\mathrm{x}, 1-\mathrm{y},-\mathrm{z}$ \\
\hline
\end{tabular}


Table 4. Geometrical parameters $\left(\AA,^{\circ}\right)$ for $\mathrm{C}-\mathrm{H} \cdots \pi$ interactions.

\begin{tabular}{|c|c|c|c|c|c|}
\hline$Y-X \cdots C g(I)$ & $\mathrm{X} \cdots \mathrm{Cg}$ & $\mathrm{Y} \cdots \mathrm{Cg}$ & $\mathrm{Y}-\mathrm{X} \cdots \mathrm{Cg}$ & X-Perp & Symmetry \\
\hline \multicolumn{6}{|c|}{ Compound (1) } \\
\hline $\mathrm{C}(2)-\mathrm{H}(2) \cdots \mathrm{Cg}(2)$ & 2.96 & $3.570(5)$ & 123 & 2.89 & $1+x, y, z$ \\
\hline $\mathrm{C}(23)-\mathrm{H}(23 \mathrm{C}) \cdots \mathrm{Cg}(4)$ & 2.98 & $3.560(5)$ & 119 & 2.73 & $\begin{array}{c}-x, 2-y, 1 \\
-z\end{array}$ \\
\hline \multicolumn{6}{|c|}{ Compound (2) } \\
\hline $\mathrm{C}(28)-\mathrm{H}(28) \cdots \mathrm{Cg}(18)$ & 2.96 & $3.413(4)$ & 110 & 2.80 & $1+x, y, z$ \\
\hline
\end{tabular}

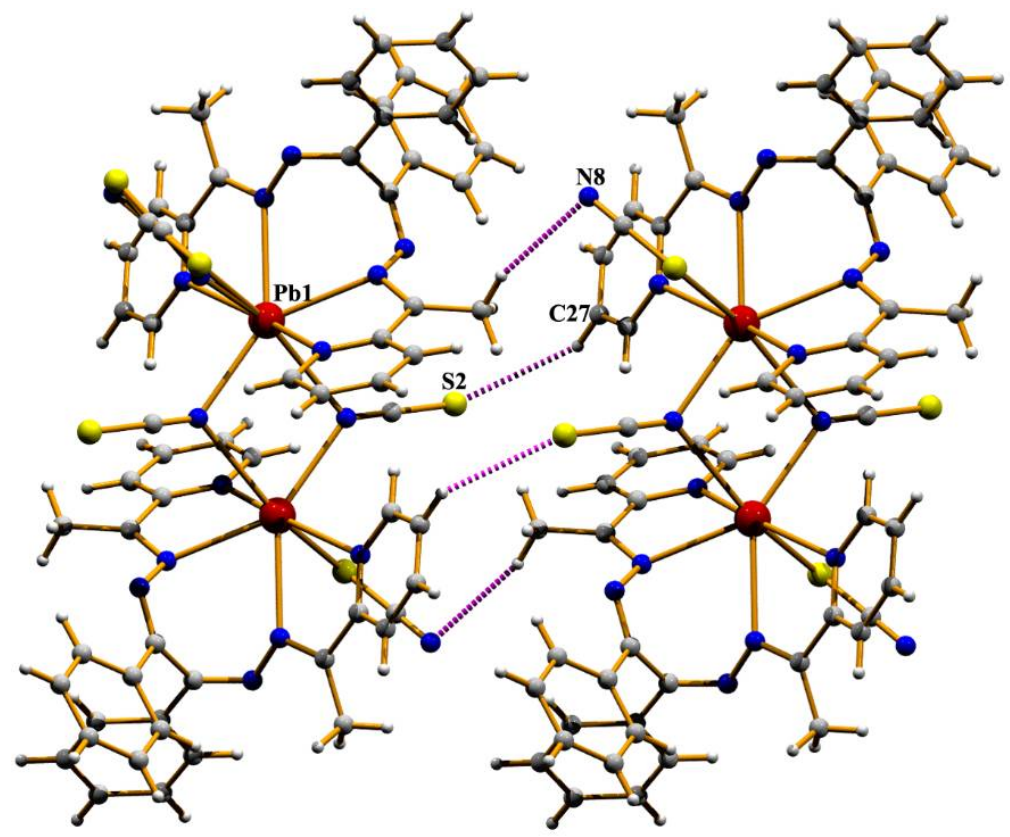

Figure 2. Partial view of the X-ray structure of (1) with indication of $\mathrm{C}-\mathrm{H} \cdots \mathrm{N}$ and $\mathrm{C}-\mathrm{H} \cdots \mathrm{N}$ H-bonds.

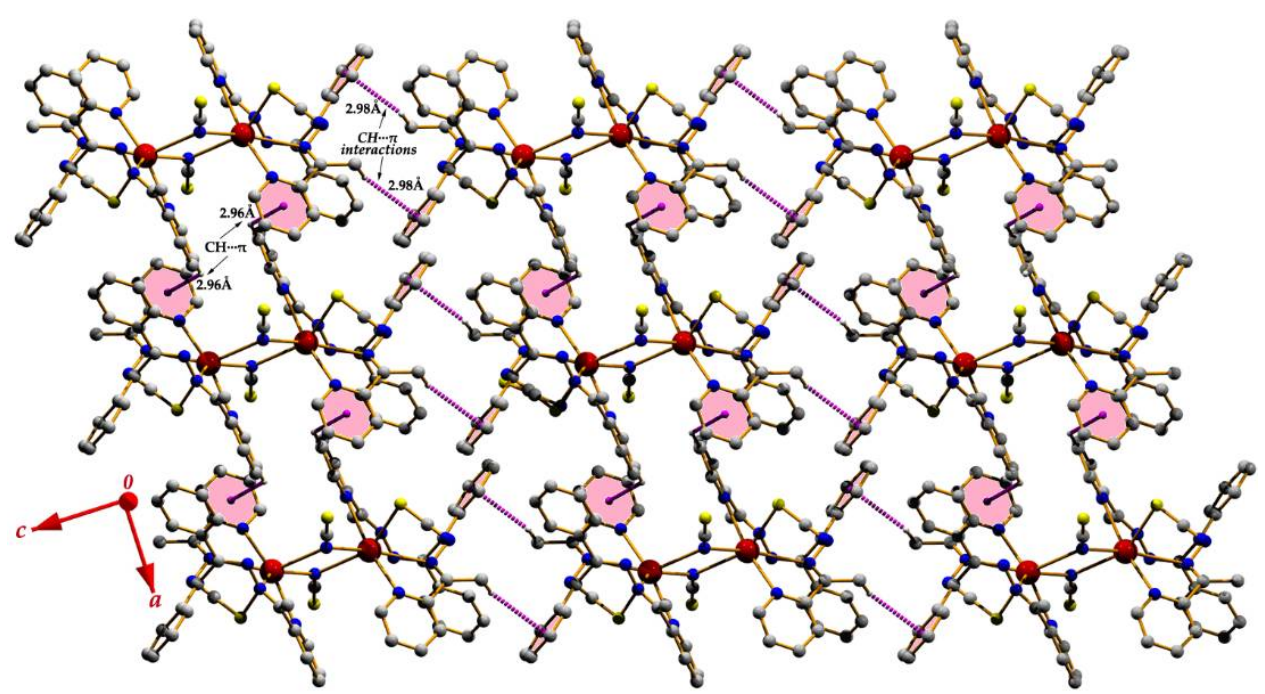

Figure 3. Self-assembled supramolecular framework in (1) in (101) plane through C-H $\cdots \pi$ interactions.

Compound (1): $\mathrm{Cg}(2)$ and $\mathrm{Cg}(4)$ are the centroids of the rings generated through the atoms (N6/C24-C28) and (C16-C21), respectively. Compound (2): $\mathrm{Cg}(18)$ is the centroid of the ring generated through the atoms $(\mathrm{N} 1 / \mathrm{C} 1-\mathrm{C} 5)$. 
Complex (2) crystallizes in the triclinic space group $P-1$ with half of the complex and one lattice $\mathrm{MeOH}$ molecule in the asymmetric unit (Figure 4). Each metal center is nine-coordinated by two pyridyl-imine units of the parent ligand $\mathrm{L}$, two types of bidentate nitrate anions (one terminal and one bridging ligand) and one monodentate nitrato bridging ligand. The ORTEP view of complex (2) is included in Figure 4 and, as noticed, the bond lengths and bond angles are in normal range (Table 2) and are comparable with related structures reported earlier [2,9]. The carbon atoms (C11-C15) of one phenyl ring are disordered over two sets of sites and refined with half-occupancies.

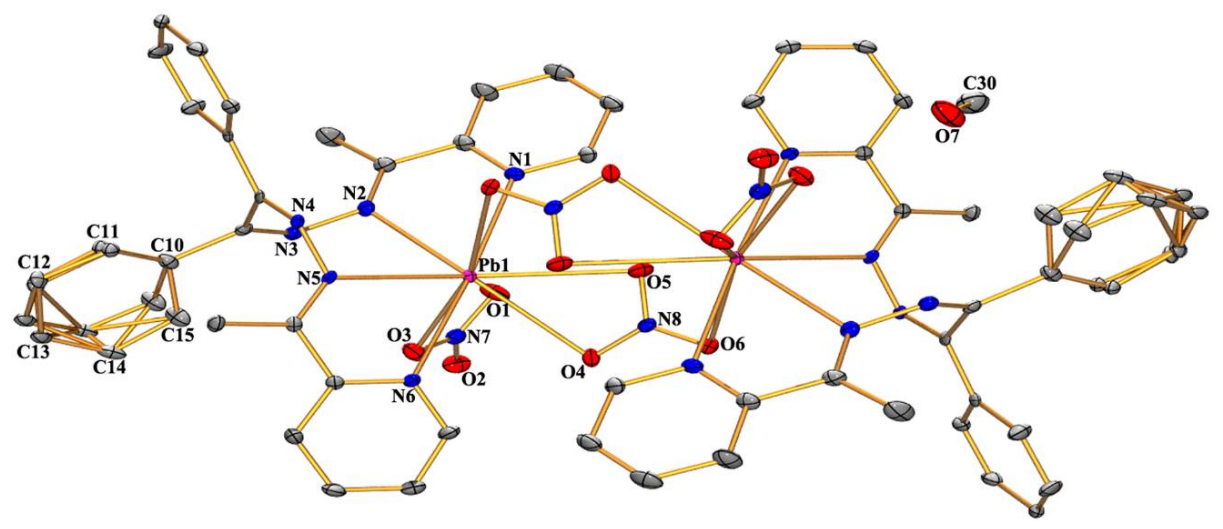

Figure 4. View of the asymmetric unit of compound (2) with partial atom numbering scheme. Hydrogen atoms are omitted for clarity. The unlabeled counterpart is generated through the symmetry operation. Thermal ellipsoids are drawn at the $30 \%$ probability level.

In the solid-state, compound (2) is stabilized through weak $\mathrm{C}-\mathrm{H} \cdots \mathrm{O}$ and $\mathrm{C}-\mathrm{H} \cdots \mathrm{N}$ unconventional hydrogen bonds and $\mathrm{C}-\mathrm{H} \cdots \pi$ interactions (Tables 3 and 4 ). In one substructure, the aryl ring carbon atom $\mathrm{C} 21$ interacts with the nitrate oxygen atom $\mathrm{O} 4$ at $(-1-\mathrm{x},-\mathrm{y},-\mathrm{z})$; therefore, forming a centrosymmetric dimeric ring centered at $(1 / 2,0,0)$ (see Figure 5). These dimeric rings lead the molecules to propagate along the [010] direction. These parallel chains are further interconnected through the C7-H7B $\cdots \mathrm{N} 3$ hydrogen bonds by generating another centrosymmetric dimer centered at $\left(0, \frac{1}{2}, \frac{1}{2}\right)$. The interconnection of these two centrosymmetric dimeric rings generates a supramolecular framework in the (011) plane (see Figure 5).

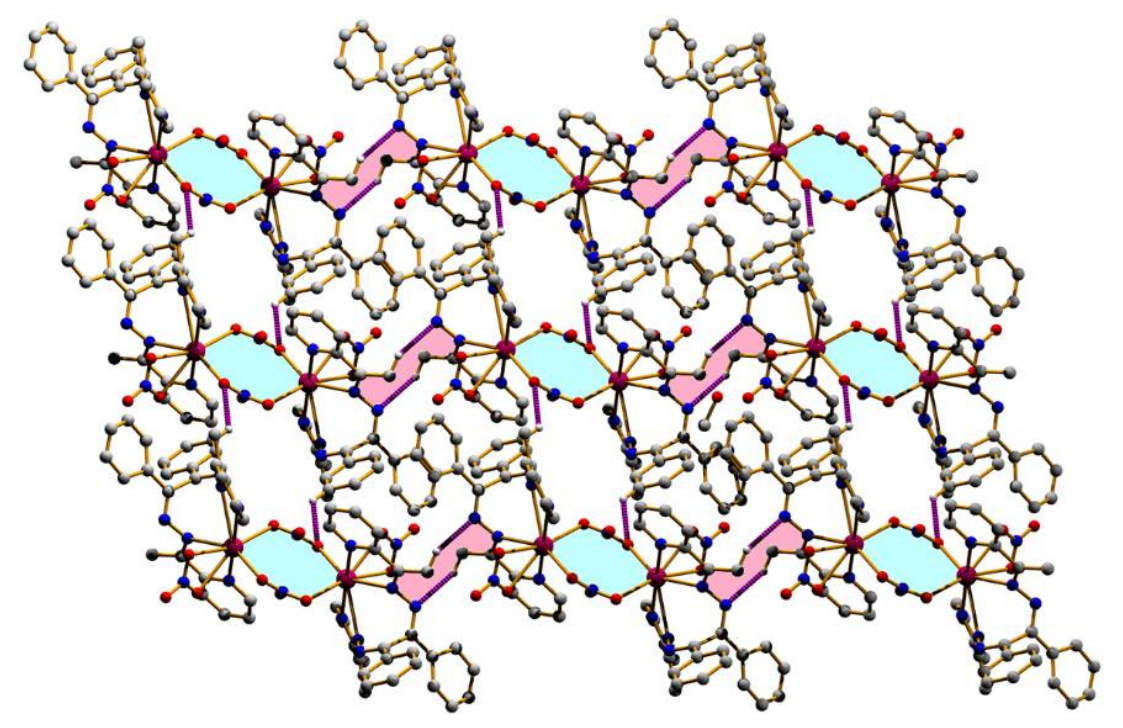

Figure 5. Two-dimensional framework generated through $\mathrm{C}-\mathrm{H} \cdots \mathrm{O}$ and $\mathrm{C}-\mathrm{H} \cdots \mathrm{N}$ hydrogen bonds in the (011) plane. 
In another substructure, compound (2) generates a network in the (110) plane through weak $\mathrm{C}-\mathrm{H} \cdots \mathrm{O}$ bonds where $\mathrm{C} 3-\mathrm{H} 3$ and $\mathrm{C} 12-\mathrm{H} 12$ groups acts as donors to the $\mathrm{O} 2$ and $\mathrm{O} 1$ atoms at $(-1+\mathrm{x}$, $y, z)$ and $(x,-1+y, z)$, respectively (Figure 6 and Table 3$)$. The pyridine ring via the $\mathrm{C} 28-\mathrm{H} 28$ group acts as a donor to the centroid of another pyridine ring of the partner molecule at $(1+x, y, z)$ to build another network in (2) (see Figure 7 and Table 4).

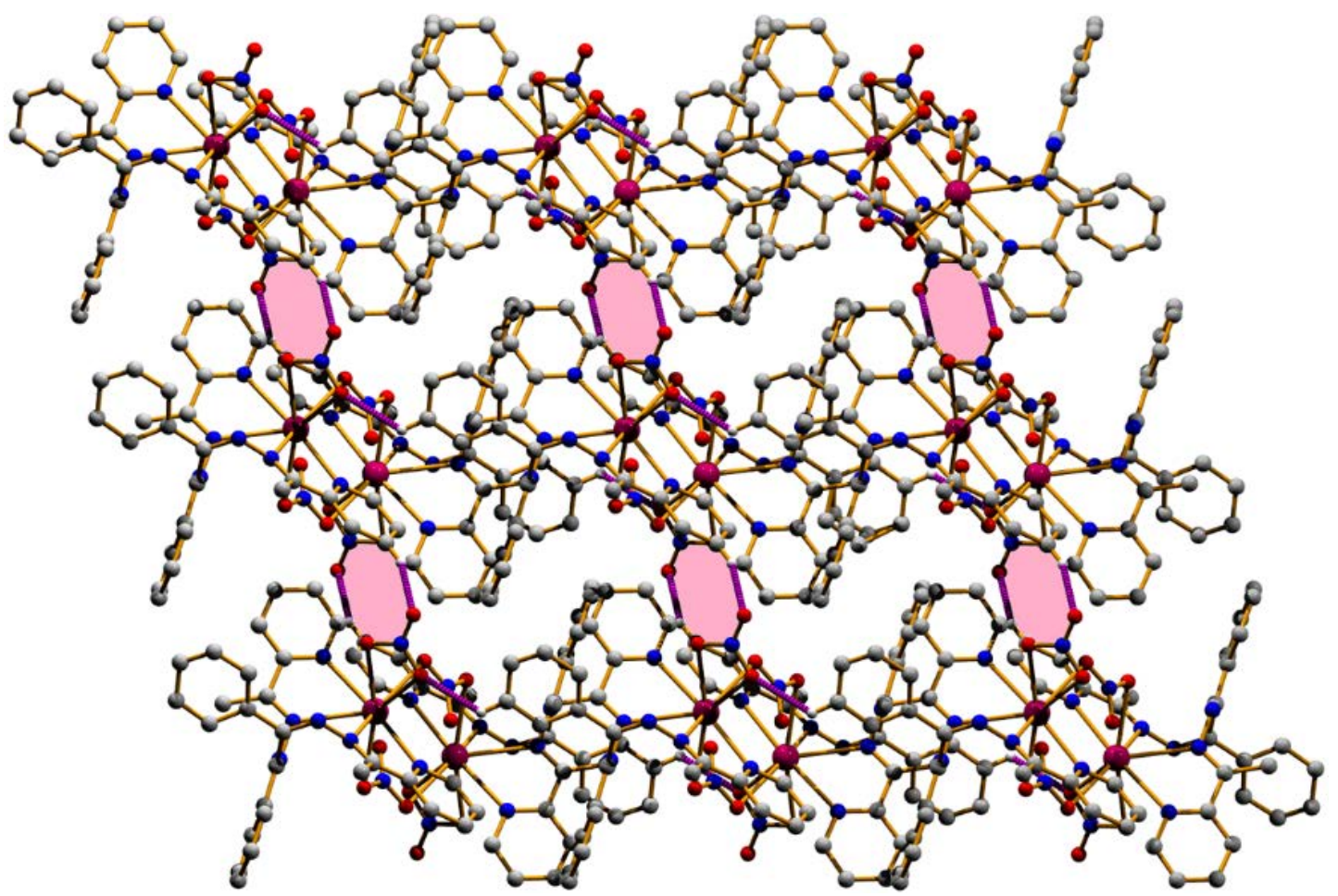

Figure 6. Supramolecular self-assembly generated through weak C-H‥O hydrogen bonds in the (110) plane.

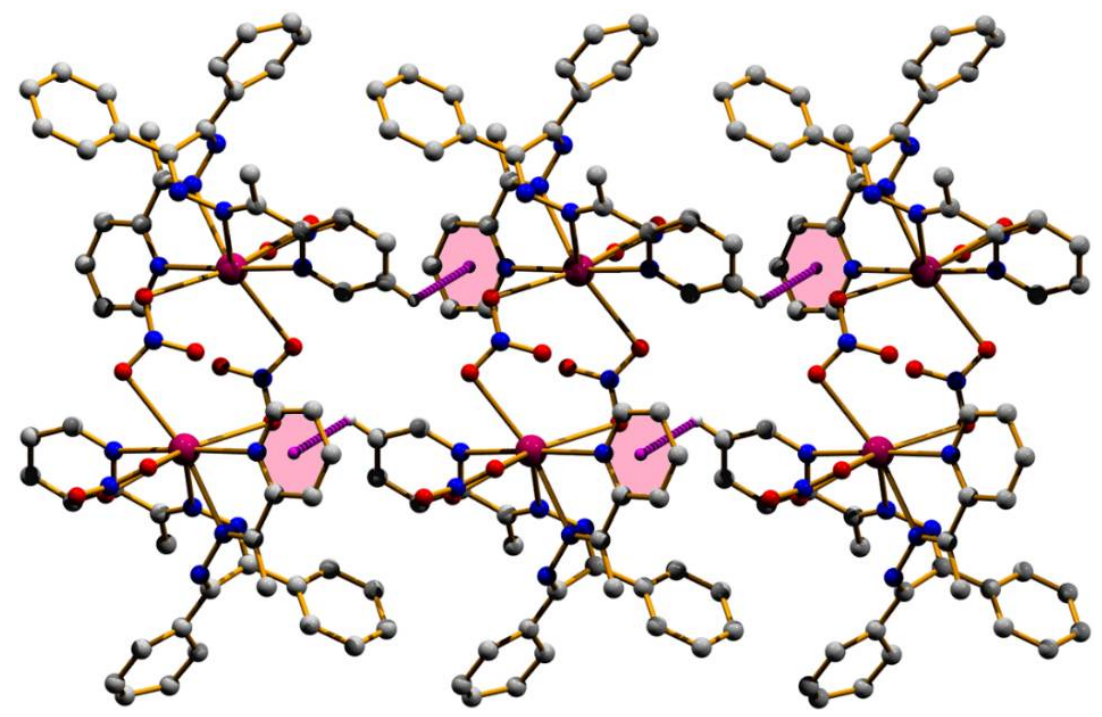

Figure 7. Perspective view of the supramolecular network through C-H $\cdots \pi$ interactions in (2).

\subsection{Hirshfeld Surface}

We have examined the Hirshfeld surfaces to quantify the contribution of noncovalent interactions in the crystal packing. In the present study, we have evaluated the contacts that are responsible in 
building the supramolecular assemblies. The symmetry-generated counterparts of the structures were not included in the Hirshfeld surface calculations. The Hirshfeld surface of compounds (1) and (2) are mapped over $d_{\text {norm }}$ in Figure 8 (in the ranges $(-0.3775$ to $1.6794 \AA)$ in (1) and (-0.5624 to $1.3287 \AA$ ) in (2)) and fragment patches (0.000 to $25.000 \AA$ in (1) and 0.000 to $29.000 \AA$ in (2), respectively). The $d_{\text {norm }}$ surfaces (Figure 8a,b) have been plotted based on the normalized function $d_{i}$ and $d_{e}$ using a white, red and blue color scheme. The circular deep red spots that are noticeable on the $d_{\text {norm }}$ surface of both compounds are due to the coordination bonds, since the symmetrically generated counterparts (see Figures 1 and 4) have not been included in the calculation. The nearest neighbor coordination environment of the molecules is identified from the color patches on the Hirshfeld surface based on their closeness to adjacent molecules. Therefore, the fragment patches show the appropriate approach for the identification of the nearest neighboring coordination environment of compounds (1) and (2) (see Figure $8 c, d$ ).

(a)

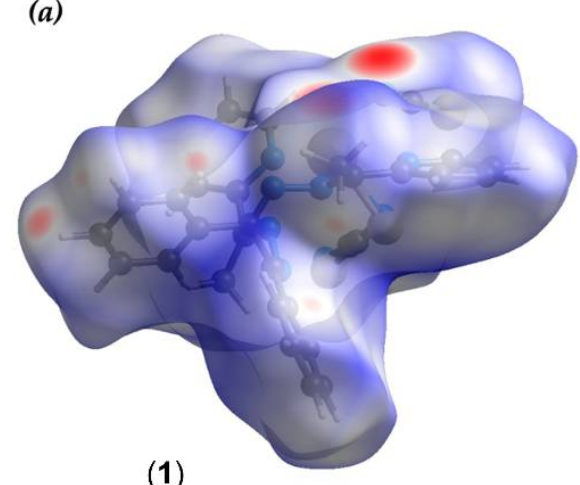

(1)

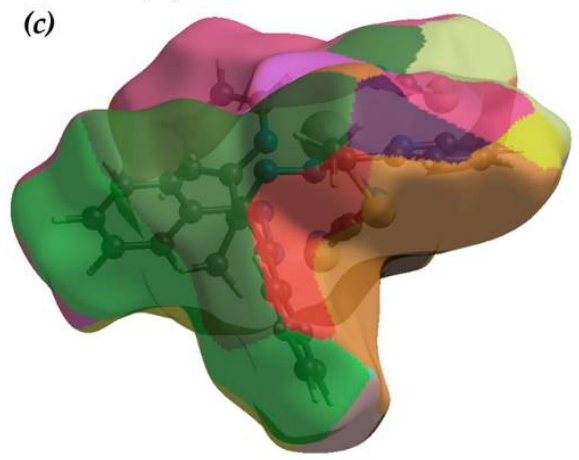

(b)

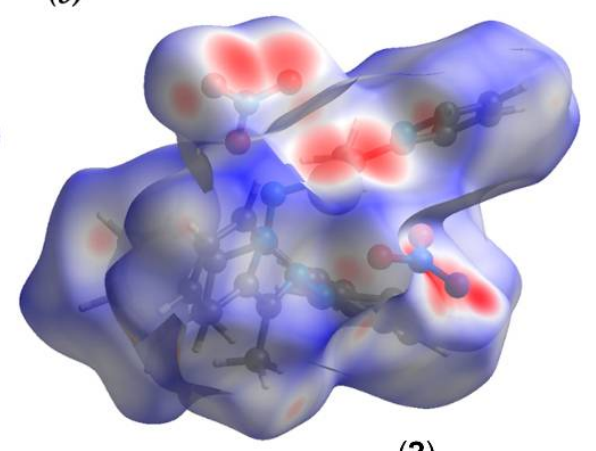

(2)

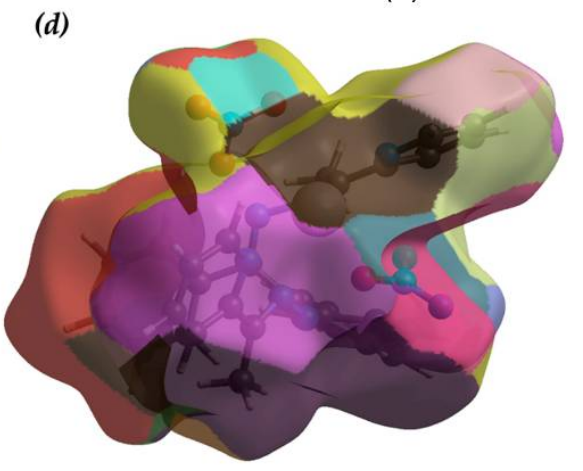

Figure 8. Hirshfeld surfaces mapped with $d_{\text {norm }}((\mathbf{a})$ and $(\mathbf{b}))$ and Fragment patches $((\mathbf{c})$ and $(\mathbf{d}))$ for compounds (1) and (2), respectively.

The scattered points of the fingerprint plots (Figures 9 and 10) evidence all interactions involved within the structures. The long coordination bonds $(\mathrm{Pb} \cdots \mathrm{N} / \mathrm{N} \cdots \mathrm{Pb})$ and $(\mathrm{Pb} \cdots \mathrm{O} / \mathrm{O} \cdots \mathrm{Pb})$ are characterized in the fingerprint plots of (1) and (2), respectively. In (2), the $(\mathrm{Pb} \cdots \mathrm{O} / \mathrm{O} \cdots \mathrm{Pb})$ contacts contributed $1.7 \%$ to the total surface area of $(2)$, whereas compound $(1)$ contributed $1.9 \%$ due to $(\mathrm{Pb} \cdots \mathrm{N} / \mathrm{N} \cdots \mathrm{Pb})$ interaction (See Figures 9 and 10). In $(2),(\mathrm{O} \cdots \mathrm{H} / \mathrm{H} \cdots \mathrm{O})$ interaction comprises $28.5 \%$, whereas compound (1) contributed $17.8 \%(\mathrm{~S} \cdots \mathrm{H} / \mathrm{H} \cdots \mathrm{S})$ interactions. The $\mathrm{N} \cdots \mathrm{H} / \mathrm{H} \cdots \mathrm{N}$ interactions for both compounds are verified by two distinct spikes on the fingerprint plot (see Figures 9 and 10). The contribution of $\mathrm{C} \cdots \mathrm{H} / \mathrm{H} \cdots \mathrm{C}$ contacts is higher in compound (1) compared to compound (2), and for both structures the $\mathrm{C} \cdots \mathrm{H}$ contact contributed more than its $\mathrm{H} \cdots \mathrm{C}$ counterpart. Moreover, the wings on the fingerprint plot of both structures designate the presence of $\mathrm{C}-\mathrm{H} \cdots \pi$ interaction. The total $\mathrm{C} \cdots \mathrm{H} / \mathrm{H} \cdots \mathrm{C}$ contacts comprise $29.2 \%$ and $22.1 \%$ in compounds (1) and (2), respectively. All other contacts that are involved within the structures of the title compounds are quantified accordingly and are included in Figures 9 and 10. 

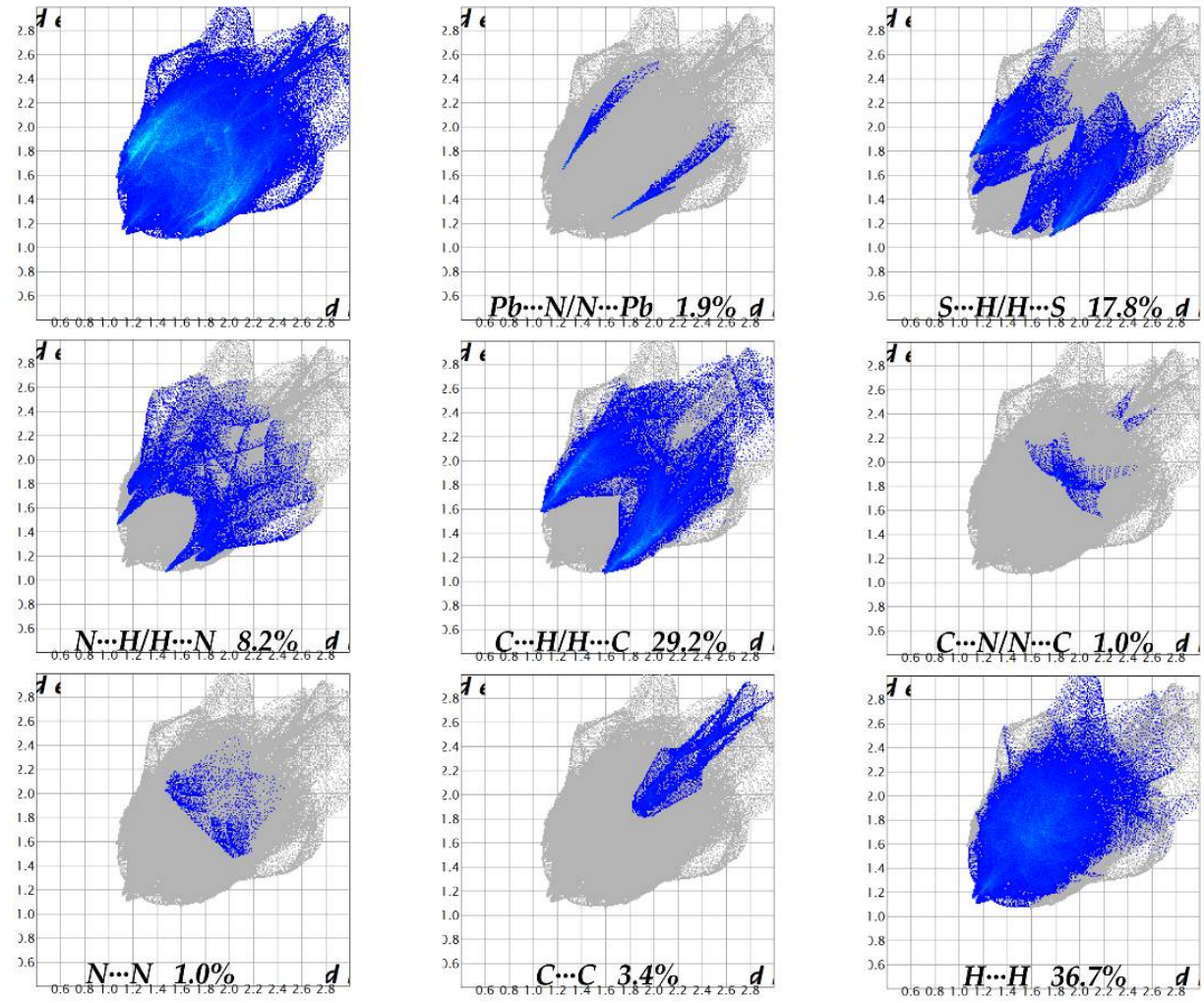

Figure 9. Full and decomposed fingerprint plots corresponding to various contacts involved within the structure of compound (1).
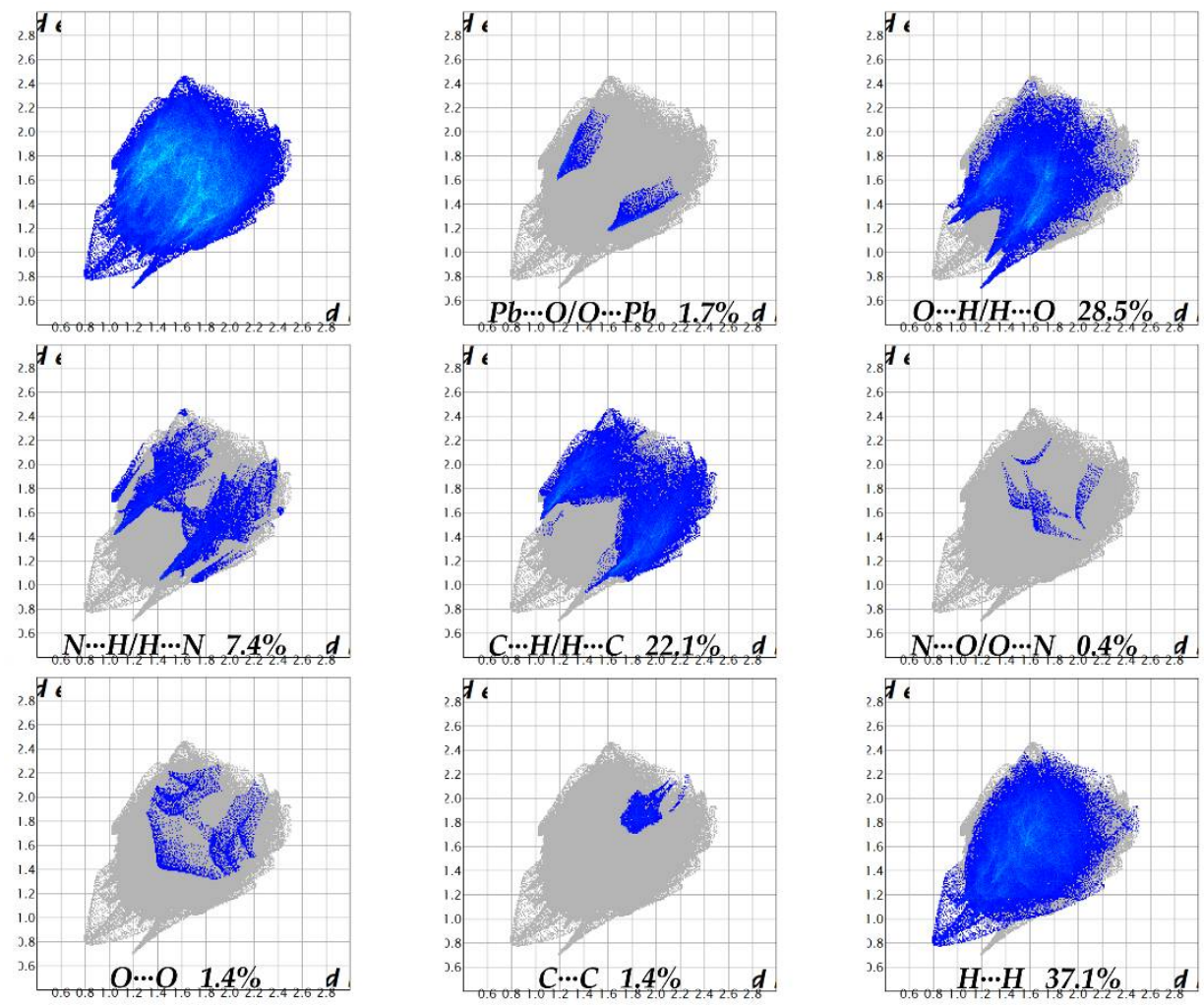

Figure 10. Full and decomposed fingerprint plots corresponding to various contacts involved within the structure of compound (2). 


\subsection{Mep Surface Analysis}

In order to rationalize the noncovalent interactions described above in the crystal packing of compounds (1) and (2), the molecular electrostatic potential (MEP) surfaces have been computed for both compounds using the asymmetric unit. The MEP surface of compound (1) is shown in Figure 11, and it shows that the most negative MEP is located at the negative belt around the S-atom of the $\mathrm{N}$-coordinated thiocyanate ligand (see Figure 11a). The MEP at the extension of the $\mathrm{C}=\mathrm{S}$ bond is significantly smaller (in absolute value) than that at the belt. The MEP value at the $\mathrm{N}$-atom of the S-coordinated thiocyanate ligand is slightly smaller $(-52 \mathrm{kcal} / \mathrm{mol})$. The most positive MEP value is located at the aromatic $\mathrm{H}$-atoms of the $\mathrm{Pb}$ (II)-coordinated pyridine ring $(+35 \mathrm{kcal} / \mathrm{mol})$ due to inductive effects. The MEP value over the aromatic phenyl ring is slightly negative $(-4 \mathrm{kcal} / \mathrm{mol})$. The MEP values are also positive at the $\mathrm{H}$-atoms of the methyl group and the phenyl rings. The formation of dinuclear centrosymmetric dimers, as observed in the X-ray structure, is favored electrostatically since the MEP value at the $\mathrm{Pb}(\mathrm{II})$ atom is positive $(+10 \mathrm{kcal} / \mathrm{mol})$ and negative at the $\mathrm{N}$-atom of the thiocyanate ligand $(-49 \mathrm{kcal} / \mathrm{mol})$. In addition, the formation of the supramolecular H-bonded self-assembled dimers in (1) shown in Figure 2 strongly agrees with the MEP surface analysis, since the H-bond acceptors ( $\mathrm{S}$ and $\mathrm{N}$-atoms of the anionic ligands) correspond to the atoms bearing the most negative MEP values. Moreover, the $\mathrm{H}$-bond donors are either an aromatic $\mathrm{H}$-atom of the coordinated pyridine ring (in the $\mathrm{C}-\mathrm{H} \cdots \mathrm{S} \mathrm{H}$-bond) or an $\mathrm{H}$-atom of the methyl group (in the $\mathrm{C}-\mathrm{H} \cdots \mathrm{N} \mathrm{H}$-bond) that correspond to the regions where the MEP value is maximum.

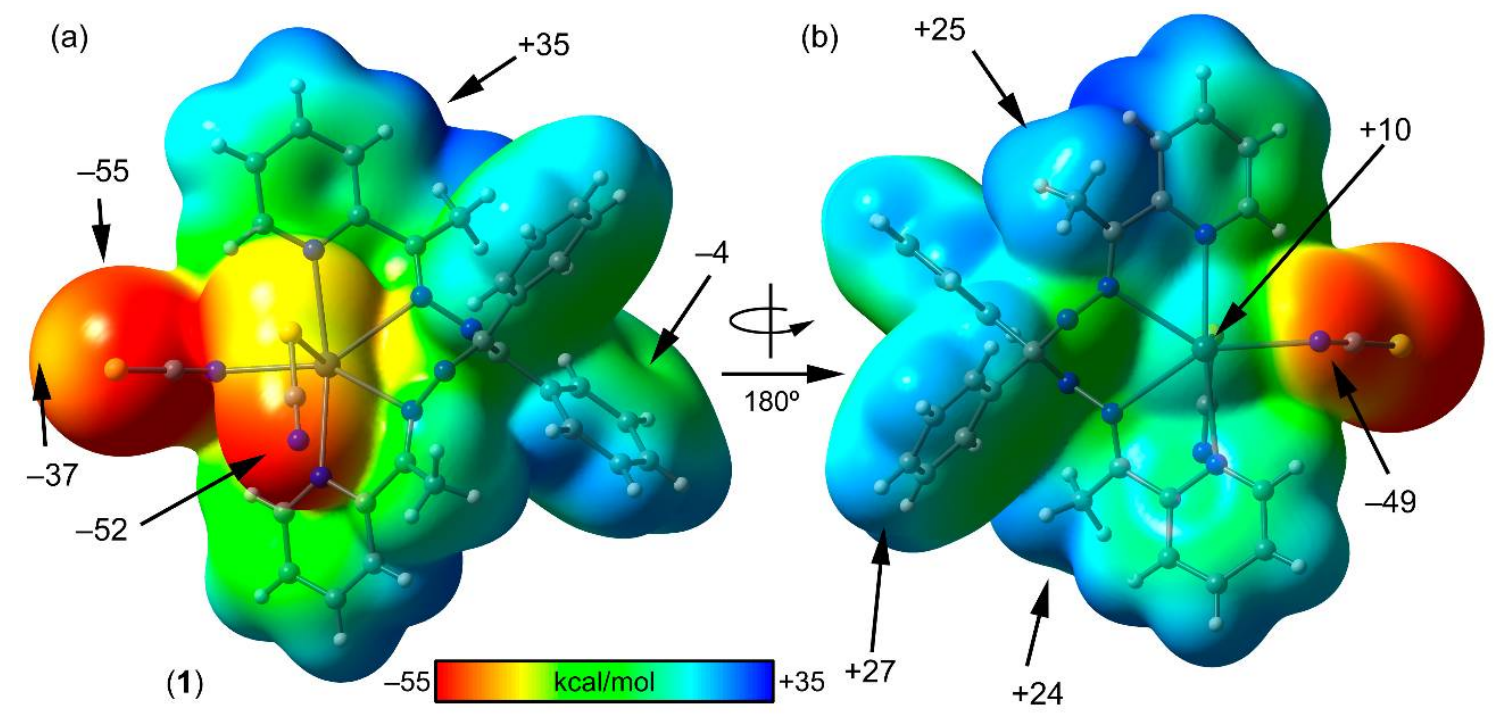

Figure 11. Molecular electrostatic potential (MEP) surface (isosurface 0.001 a.u.) of the two sides (a) and (b) of compound (1) at the PBE1PBE-D3/def2-TZVP. The MEP values at selected points of the surface are given in $\mathrm{kcal} / \mathrm{mol}$.

The MEP surface of compound (2) is shown in Figure 12, showing that the most negative MEP is located at the equatorial nitrato ligand $(-60 \mathrm{kcal} / \mathrm{mol})$. The MEP at the $\mathrm{O}$-atom of the axial nitrato ligand is slightly smaller in absolute value $(-55 \mathrm{kcal} / \mathrm{mol})$. Similarly to compound (1), the most positive MEP value is located at the aromatic $\mathrm{H}$-atoms of the $\mathrm{Pb}(\mathrm{II})$-coordinated pyridine ring $(+32 \mathrm{kcal} / \mathrm{mol})$, due to the enhancement of their acidity upon complexation. The MEP value over the aromatic phenyl ring is slightly negative $(-1 \mathrm{kcal} / \mathrm{mol})$, and positive over the coordinated pyridine ligand $(+8 \mathrm{kcal} / \mathrm{mol})$. The MEP values are also positive at the $\mathrm{H}$-atoms of the methyl group $(+23 \mathrm{kcal} / \mathrm{mol})$ and the phenyl rings $(+21 \mathrm{kcal} / \mathrm{mol})$. The formation of the dinuclear centrosymmetric dimer, as observed in the $\mathrm{X}$-ray structure, is more favored electrostatically than that in (1) since the MEP value at the $\mathrm{Pb}$ (II) atom is more positive $(+22 \mathrm{kcal} / \mathrm{mol})$, and at the $\mathrm{O}$-atom of the nitrato ligand $(-49 \mathrm{kcal} / \mathrm{mol}) \mathrm{more}$ negative than those of compound (1) (see Figure 11). Moreover, the formation of the two-dimensional 
network in compound (2) generated through $\mathrm{C}-\mathrm{H} \cdots \mathrm{O}$ hydrogen bonds in the (011) plane (see Figure 5) also agrees well with the MEP surface of (2), since the H-bond acceptor is the most negative O-atom. The $\mathrm{C}-\mathrm{H} \cdots \mathrm{N}$ bonds that are also formed in the $2 \mathrm{D}$ layer are expected to be weaker, since the MEP value at the non-coordinated $\mathrm{N}$-atom of the ligand is only $-5 \mathrm{kcal} / \mathrm{mol}$ (see Figure 11a). This is also in good agreement with the Hirshfeld surface analysis of (2), since the quantification of the contribution of the $\mathrm{O} \cdots \mathrm{H} / \mathrm{H} \cdots \mathrm{O}$ contacts is $28.5 \%$ and the contribution of the $\mathrm{N}-\mathrm{H} / \mathrm{H}-\mathrm{N}$ contacts is only $7.4 \%$.

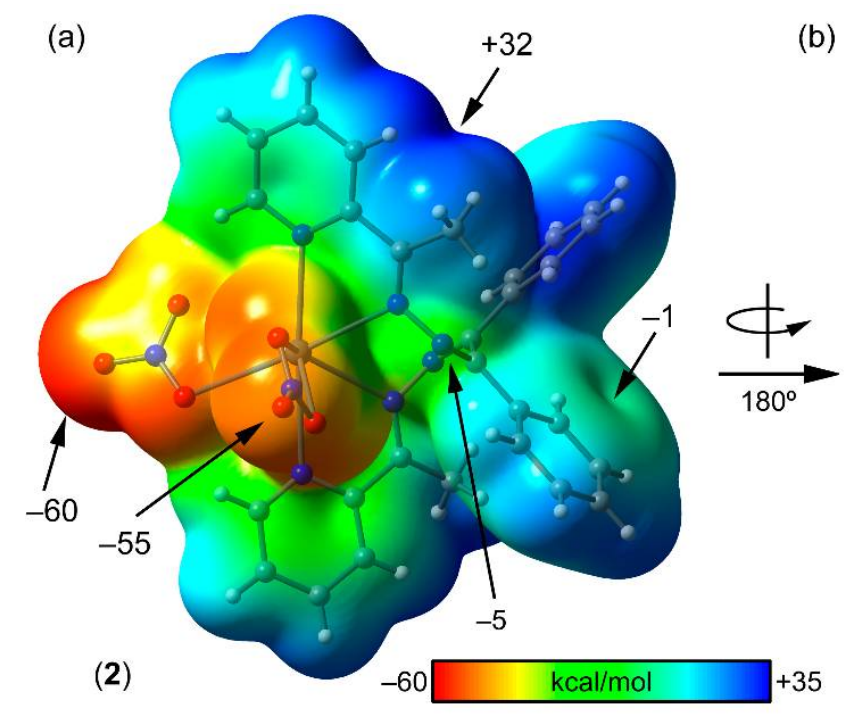

(b)

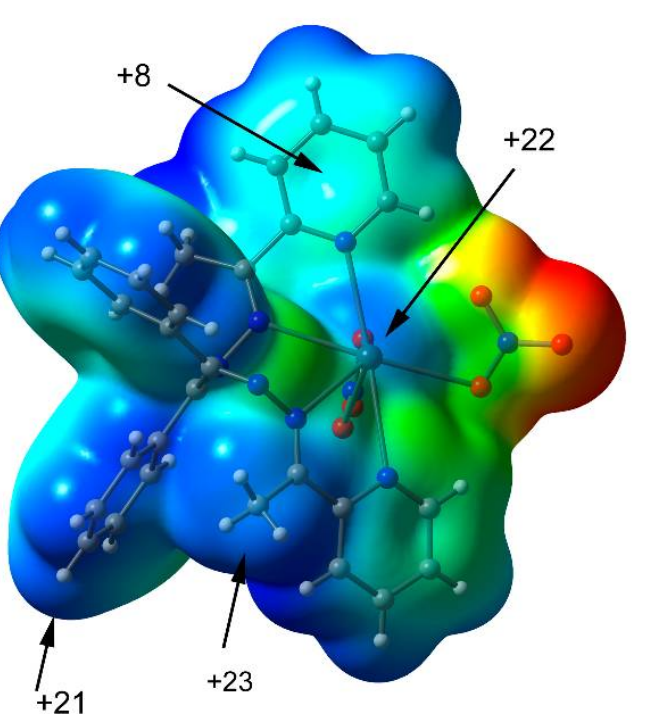

Figure 12. MEP surface (isosurface 0.001 a.u.) of the two sides (a) and (b) of compound (2) at the PBE1PBE-D3/def2-TZVP. The MEP values at selected points of the surface are given in $\mathrm{kcal} / \mathrm{mol}$.

\section{Concluding Remarks}

The protocol to synthesize two new dinuclear $\mathrm{Pb}(\mathrm{II})$ coordination compounds involving 1,2-diphenyl-1,2-bis((methyl(pyridin-2-yl)methylene)hydrazono)ethane ligand and $\mathrm{SCN}^{-}$and $\mathrm{NO}_{3}{ }^{-}$ counter anions is reported in this manuscript. Both complexes were characterized in the solid state by X-ray diffraction. The crystal packing of both compounds is dominated by $\mathrm{C}-\mathrm{H} \cdots \mathrm{O}, \mathrm{N}, \mathrm{S}$ noncovalent interactions, which is further evidenced by the Hirshfeld surface analysis and rationalized using the MEP surface analysis. The latter demonstrates that the most electron rich regions of the complexes that correspond to the anionic coligands are the most electron poor to the aromatic $\mathrm{H}$-atoms, thus favoring the $\mathrm{C}-\mathrm{H} \cdots \mathrm{O}, \mathrm{N}, \mathrm{S} \mathrm{H}-$ bonds. Moreover, although the ligand presents an extended aromatic surface (composed by four aromatic rings) $\pi-\pi$ interactions are not observed. Interestingly, $\mathrm{C}-\mathrm{H} \cdots \pi$ interactions seem to dominate the crystal packing in both compounds (1) and (2).

Author Contributions: Conceptualization, A.F. and G.M.; methodology, F.I.Z.; software, A.F. and S.K.S.; investigation, all authors; writing-original draft preparation, A.B.R., A.F. and S.K.S. writing-review and editing, all authors; visualization, A.F. and S.K.S.; project administration, A.F. and F.I.Z.; funding acquisition, A.F. and F.I.Z. All authors have read and agreed to the published version of the manuscript.

Funding: The publication has been prepared with the support of the "RUDN University Program 5-100" (recipient F. I. Zubkov, synthesis of the ligands). This research was funded by the MICIU/AEI of Spain (project CTQ2017-85821-R FEDER funds).

Acknowledgments: We thank the "Centre de Tecnologies de la Informació" (CTI), Universitat de les Illes Balears for computational facilities. We also thank all projects for financial support.

Conflicts of Interest: The authors declare no conflict of interest. 


\section{References}

1. Casas, J.S.; Sordo, J. Lead: Chemistry, Analytical Aspects, Environmental Impact and Health Effects; Elsevier: Amsterdam, The Netherlands, 2006.

2. Bauzá, A.; Seth, S.K.; Frontera, A. Tetrel bonding interactions at work: Impact on tin and lead coordination compounds. Coord. Chem. Rev. 2019, 384, 107-125. [CrossRef]

3. Reger, D.L.; Wright, T.D.; Little, C.A.; Lamba, J.J.S.; Smith, M.D. Control of the Stereochemical Impact of the Lone Pair in Lead(II) Tris(pyrazolyl)methane Complexes. Improved Preparation of $\mathrm{Na}\left\{\mathrm{B}\left[3,5-\left(\mathrm{CF}_{3}\right)_{2} \mathrm{C}_{6} \mathrm{H}_{3}\right]_{4}\right\}$. Inorg. Chem. 2001, 40, 3810-3814. [CrossRef] [PubMed]

4. Fleischer, H.; Schollmeyer, D. Synthesis of and Structural Studies on Lead(II) Cysteamin Complexes. Inorg. Chem. 2004, 43, 5529-5536. [CrossRef] [PubMed]

5. Mahmudov, K.T.; Gurbanov, A.V.; Guseinov, F.I.; Guedes da Silva, M.F.C. Noncovalent interactions in metal complex catalysis. Coord. Chem. Rev. 2019, 387, 32-46. [CrossRef]

6. Olvera, A.; Shi, G.; Djieutedjeu, H.; Page, A.; Uher, C.; Kioupakis, E.; Poudeu, P.F.P. Pb ${ }_{7} B_{4} \mathrm{Se}_{13}$ : A Lillianite Homologue with Promising Thermoelectric Properties. Inorg. Chem. 2015, 54, 746-755. [CrossRef]

7. Mahmoudi, G.; Bauzá, A.; Frontera, A. Concurrent agostic and tetrel bonding interactions in lead(ii) complexes with an isonicotinohydrazide based ligand and several anions. Dalton Trans. 2016, 45, 4965-4969. [CrossRef]

8. Roy, S.; Drew, M.G.B.; Bauzá, A.; Frontera, A.; Chattopadhyay, S. Non-covalent tetrel bonding interactions in hemidirectional lead(II) complexes with nickel(II)-salen type metallo-ligands. New J. Chem. 2018, 42, 6062-6076. [CrossRef]

9. Mahmoudi, G.; Seth, S.K.; Zubkov, F.I.; López-Torres, E.; Bacchi, A.; Stilinović, V.; Frontera, A. Supramolecular Assemblies in $\mathrm{Pb}(\mathrm{II})$ Complexes with Hydrazido-Based Ligands. Crystals 2019, 9, 323. [CrossRef]

10. Servati, G.M.; Stilinović, V.; Bauzá, A.; Frontera, A.; McArdle, P.; Van Derveer, D.; Ng, S.W.; Mahmoudi, G. Design of Lead(II) Metal-Organic Frameworks Based on Covalent and Tetrel Bonding. Chem. Eur. J. 2015, 21, 17951-17958. [CrossRef] [PubMed]

11. John, R.P.; Park, M.; Moon, D.; Lee, K.; Hong, S.; Zou, Y.; Hong, C.S.; Lah, M.S.A. A chiral pentadecanuclear metallamacrocycle with a sextuple twisted möbius topology. J. Am. Chem. Soc. 2007, 129, 14142-14143. [CrossRef]

12. De, S.; Drew, M.G.B.; Rzepa, H.S.; Datta, D. Linking number analysis of a self-assembled lemniscular Möbius-metallamacrocycle. New J. Chem. 2008, 32, 1831-1834. [CrossRef]

13. Rzepa, H.S. Linking number analysis of a pentadecanuclear metallamacrocycle: A möbius-craig system revealed. Inorg. Chem. 2008, 47, 8932-8934. [CrossRef] [PubMed]

14. Sankar, J.; Mori, S.; Saito, S.; Rath, H.; Suzuki, M.; Inokuma, Y.; Shinokubo, H.; Kim, K.S.; Yoon, Z.S.; Shin, J.Y.; et al. Unambiguous identification of Möbius aromaticity for meso-aryl-substituted [28]hexaphyrins(1.1.1.1.1.1). J. Am. Chem. Soc. 2008, 130, 13568-13579. [CrossRef] [PubMed]

15. Sung, Y.M.; Yoon, M.C.; Lim, J.M.; Rath, H.; Naoda, K.; Osuka, A.; Kim, D. Reversal of Hückel (anti)aromaticity in the lowest triplet states of hexaphyrins and spectroscopic evidence for Baird's rule. Nat. Chem. 2015, 7, 418-422. [CrossRef]

16. Masoumi, A.; Gargari, M.S.; Mahmoudi, G.; Machura, B.; Lynch, V.; Giester, G.; Abedi, M.; Hazendonk, P. Structural diversity in manganese(II) complexes with multidentate N-donor imino pyridyl ligands. Z. Anorg. Allg. Chem. 2015, 641, 1176-1181. [CrossRef]

17. Mahmoudi, G.; Stilinović, V.; Gargari, M.S.; Bauzá, A.; Zaragoza, G.; Kaminsky, W.; Lynch, V.; Choquesillo-Lazarte, D.; Sivakumar, K.; Khandari, A.A.; et al. From monomers to polymers: Steric and supramolecular effects on dimensionality of coordination architectures of heteroleptic mercury(ii) halogenide-tetradentate Schiff base complexes. CrystEngComm 2015, 17, 3493-3502. [CrossRef]

18. Mahmoudi, G.; Zaręba, J.K.; Gurbanov, A.V.; Bauzá, A.; Zubkov, F.I.; Kubicki, M.; Stilinović, V.; Kinzhybalo, V.; Frontera, A. Benzyl Dihydrazone versus Thiosemicarbazone Schiff Base: Effects on the Supramolecular Arrangement of Cobalt Thiocyanate Complexes and the Generation of $\mathrm{CoN}_{6}$ and $\mathrm{CoN}_{4} \mathrm{~S}_{2}$ Coordination Spheres. Eur. J. Inorg Chem. 2017, 4763-4772. [CrossRef]

19. Afkhami, F.A.; Mahmoudi, G.; Gurbanov, A.V.; Zubkov, F.I.; Qu, F.; Gupta, A.; Safin, D.A. Solvent-driven azide-induced mononuclear discrete versus one-dimensional polymeric aromatic Möbius cadmium(ii) complexes of an $\mathrm{N}_{6}$ tetradentate helical ligand. Dalton Trans. 2017, 46, 14888-14896. [CrossRef] 
20. Seth, S.K.; Bauzá, A.; Mahmoudi, G.; Stilinović, V.; López-Torres, E.; Zaragoza, G.; Keramidas, A.D.; Frontera, A. On the importance of $\mathrm{Pb} \cdots \mathrm{X}(\mathrm{X}=\mathrm{O}, \mathrm{N}, \mathrm{S}, \mathrm{Br})$ tetrel bonding interactions in a series of tetra- and hexa-coordinated $\mathrm{Pb}$ (ii) compounds. CrystEngComm 2018, 20, 5033-5044. [CrossRef]

21. Mahmoudi, G.; Afkhami, F.A.; Castiñeiras, A.; García-Santos, I.; Gurbanov, A.; Zubkov, F.I.; Mitoraj, M.P.; Kukułka, M.; Sagan, F.; Szczepanik, D.W.; et al. Quasi-aromatic Möbius Metal Chelates. Inorg. Chem. 2018, 57, 4395-4408. [CrossRef]

22. Mitoraj, M.P.; Mahmoudi, G.; Afkhami, F.A.; Castiñeiras, A.; Giester, G.; Konyaeva, I.A.; Khandar, A.A.; Qu, F.; Gupta, A.; Sagan, F.; et al. Effect of Solvent on the Structural Diversity of Quasi-Aromatic Möbius Cadmium(II) Complexes Fabricated from the Bulky N 6 Tetradentate Helical Ligand. Cryst. Growth Des. 2019, 19, 1649-1659. [CrossRef]

23. Afkhami, F.A.; Mahmoudi, G.; White, J.M.; Lipkowski, J.; Konyaeva, I.A.; Safin, D.A. Möbius-like metal chelates constructed from $\mathrm{CdHal}_{2}(\mathrm{Hal}=\mathrm{Cl}, \mathrm{Br}, \mathrm{I})$ and benzilbis(pyridin-2-yl)methylidenehydrazone. Inorg. Chim. Acta 2019, 484, 481-490. [CrossRef]

24. Afkhami, F.A.; Mahmoudi, G.; Khandar, A.A.; White, J.M.; Konyaeva, I.A.; Safin, D.A. Metal chelates constructed from $\mathrm{CdHal}_{2}(\mathrm{Hal}=\mathrm{Cl}, \mathrm{Br}, \mathrm{I})$ and 1,2-diphenyl-1,2-bis((phenyl(pyridin-2yl)methylene)hydrazono)ethane. J. Molec. Struct. 2019, 1176, 743-750. [CrossRef]

25. Mitoraj, M.P.; Afkhami, F.A.; Mahmoudi, G.; Khandar, A.A.; Gurbanov, A.V.; Zubkov, F.I.; Waterman, R.; Babashkina, M.G.; Szczepanik, D.W.; Jena, H.S.; et al. Structural versatility of the quasi-aromatic Möbius type zinc(ii)-pseudohalide complexes-experimental and theoretical investigations. RSC Adv. 2019, 9, 23764-23773. [CrossRef]

26. Afkhami, F.A.; Mahmoudi, G.; Qu, F.; Gupta, A.; Zangrando, E.; Frontera, A.; Safin, D.A. Complexes of $\mathrm{BiCl}_{3}$ with hydrazone derived ligands: Möbius-like discrete metal chelate versus salt-like porous polymeric structure. Inorg. Chim. Acta 2020, 502, 119350. [CrossRef]

27. Bruker. SAINT, version 6.36a; Bruker-AXS Inc.: Madison, WI, USA, 2002.

28. Bruker. SMART, Version 5.625 and SADABS, Version 2.03a; Bruker AXS Inc.: Madison, WI, USA, 2001.

29. Sheldrick, G.M. A short history of SHELX. ActaCryst. 2008, A64, 112-122.

30. Sheldrick, G.M. Crystal structure refinement with SHELXL. ActaCryst. 2015, C71, 3-8.

31. Farrugia, L.J. WinGX suit for small-molecule single-crystal crystallography. J. Appl. Crystallogr. 1999, 32, 837-838. [CrossRef]

32. Spek, A.L. Single-crystal structure validation with the program PLATON. J. Appl. Crystallogr. 2003, 36, 7-13. [CrossRef]

33. Spackman, M.A.; McKinnon, J.J. Fingerprinting intermolecular interactions in molecular crystals. CrystEngComm 2002, 4, 378-392. [CrossRef]

34. Seth, S.K.; Saha, I.; Estarellas, C.; Frontera, A.; Kar, T.; Mukhopadhyay, S. Supramolecular Self-Assembly of M-IDA Complexes Involving Lone-Pair $\cdots \pi$ Interactions: Crystal Structures, Hirshfeld Surface Analysis, and DFT Calculations $\left[\mathrm{H}_{2} \mathrm{IDA}=\right.$ iminodiacetic acid, $\left.\mathrm{M}=\mathrm{Cu}(\mathrm{II}), \mathrm{Ni}(\mathrm{II})\right]$. Cryst. Growth Des. 2011, 11, 3250-3265. [CrossRef]

35. McKinnon, J.J.; Spackman, M.A.; Mitchell, A.S. Novel tools for visualizing and exploring intermolecular interactions in molecular crystals. Acta Cryst. 2004, B60, 627-668. [CrossRef]

36. Rohl, A.L.; Moret, M.; Kaminsky, W.; Claborn, K.; Mckinnon, J.J.; Kahr, B. Hirshfeld Surfaces Identify Inadequacies in Computations of Intermolecular Interactions in Crystals: Pentamorphic 1,8Dihydroxyanthraquinone. Cryst. Growth Des. 2008, 8, 4517-4525. [CrossRef]

37. Seth, S.K. Tuning the formation of MOFs by $\mathrm{pH}$ influence: $\mathrm{X}$-ray structural variations and Hirshfeld surface analyses of 2-amino-5-nitropyridine with cadmium chloride. Acta Cryst. 2013, 15, 1772-1781. [CrossRef]

38. Seth, S.K.; Bauzá, A.; Frontera, A. Screening polymorphism in a Ni(II) metal-organic framework: Experimental observations, Hirshfeld surface analyses and DFT studies. CrystEngComm 2018, 20, 746-754. [CrossRef]

39. Seth, S.K. Structural characterization and Hirshfeld surface analysis of a CoII complex with imidazo[1,2-a]-pyridine. Acta Cryst. 2018, E74, 600-606. [CrossRef]

40. Maity, T.; Mandal, H.; Bauza, A.; Samanta, B.C.; Frontera, A.; Seth, S.K. Quantifying conventional $\mathrm{C}-\mathrm{H} \cdots \pi(\operatorname{aryl})$ and unconventional $\mathrm{C}-\mathrm{H} \cdots \pi$ (chelate) interactions in dinuclear $\mathrm{Cu}(\mathrm{II})$ complexes: Experimental observations, Hirshfeld surface and theoretical DFT study. New J. Chem. 2018, 42, 10202-10213. [CrossRef] 
41. Wolff, S.K.; Grimwood, D.J.; McKinnon, J.J.; Jayatilaka, D.; Spackman, M.A. CrystalExplorer 3.1; University of Western Australia: Perth, Australia, 2007.

42. Frisch, M.J.; Trucks, G.W.; Schlegel, H.B.; Scuseria, G.E.; Robb, M.A.; Cheeseman, J.R.; Scalmani, G.; Barone, V.; Petersson, G.A.; Nakatsuji, H.; et al. Gaussian 16, Revision A.03; Gaussian, Inc.: Wallingford, CT, USA, 2016.

43. Adamo, C.; Barone, V. Toward reliable density functional methods without adjustable parameters: The PBE0 model. J. Chem. Phys. 1999, 110, 6158-6169. [CrossRef]

44. Grimme, S.; Antony, J.; Ehrlich, S.; Krieg, H. A dispersion correction for density functionals, Hartree-Fock and semi-empirical quantum chemical methods DFT-D3. J. Chem. Phys. 2010, 132, 154104. [CrossRef]

45. Weigend, F.; Ahlrichs, R. Balanced basis sets of split valence, triple zeta valence and quadruple zeta valence quality for H to Rn: Design and assessment of accuracy. Phys. Chem. Chem. Phys. 2005, 7, 3297-3305. [CrossRef]

46. Weigend, F. Accurate Coulomb-fitting basis sets for H to Rn. Phys. Chem. Chem. Phys. 2006, 8, 1057-1065. [CrossRef] [PubMed]

(C) 2020 by the authors. Licensee MDPI, Basel, Switzerland. This article is an open access article distributed under the terms and conditions of the Creative Commons Attribution (CC BY) license (http://creativecommons.org/licenses/by/4.0/). 